\title{
Esporte de ouro e educação "ferro velho": a nossa vida continua... na mesma!
}

Cláudio Pellini Vargas*

\begin{abstract}
Resumo: Este trabalho tem por objetivo refletir sobre o contexto olímpico esportivo atual, considerando a hierarquização institucional esportiva em relação à escolar, fato que parece comum no Brasil. Para tal, sustenta-se em recentes trabalhos de renomados intelectuais, bem como na observação atenta da cobertura televisiva dos Jogos Olímpicos de Londres, incluindo aqui uma importante entrevista com Carlos Arthur Nuzman, o presidente do Comitê Olímpico Brasileiro (COB). Para Bracht, a lógica que define as ações no campo esportivo não é influenciada pelos resultados educativos. Argumento, então, que os resultados esportivos geram influências bastante questionáveis no campo educacional.
\end{abstract}

Palavras-chave: Esportes. Educação. Conhecimento. Jogos Olímpicos.

\section{CONSIDERAÇões INICIAIS}

Mas, o que há, enfim, de tão perigoso no fato de as pessoas falarem e de seus discursos proliferarem indefinidamente? Onde, afinal, está o perigo? (FOUCAULT, 2008)

Lágrimas nos olhos! Dedicação, raça, dor, vontade... Enfim, muitas poderiam ser as palavras que bem representariam o suor dos atletas canarinhos nos Jogos Olímpicos de Londres. Embora eu possa reconhecer - com irônico louvor - que nosso governo "fez por onde" para que o Brasil trouxesse tantas medalhas (e perdesse tantas outras), fica-me uma questão mais séria: quantos milhões de reais

"Doutorando em Educação - PPGE/UFJF, Juiz de Fora, MG, Brasil. Agência de fomento: FAPEMIG. E-mail: prof.pellini@yahoo.com.br 
públicos foram investidos para que proporcionássemos toda essa festa? E que, diga-se bem, não foi "tão dourada assim". Pergunto ao leitor: existem campos mais carentes que o Esporte em nosso país? Certamente...

Mesmo quase trinta anos após a (pseudo) democratização do poder no Brasil, ainda me é assustador concluir que os líderes políticos (assim como os próprios professores em geral) se sustentam numa pobreza de valores, de cultura e da própria intelectualidade. São comuns os discursos que se reduzem a meras citações intelectuais abstratas, mas que parecem consensuais nesta segunda década do novo milênio (ou como determinada classe de pensadores tenta caracterizar: o mundo "pós"). "Escola pública e gratuita", "qualidade de ensino", "todo o conhecimento é relativo", "os currículos são conteudistas", são exemplos claros de chavões que parecem mais ganhar aplausos de plateias "seletas" do que realmente contribuir para uma transformação da sociedade. Em relação à Educação Física (EF) e ao Esporte, destaco os mais famosos: "Precisamos transformar nosso Brasil numa potência olímpica" e "O esporte educa e é bom para a saúde".

Assim posto, pretendo com este ensaio - e apoiado em recentes trabalhos de renomados intelectuais, bem como na observância atenta da cobertura televisiva dos Jogos Olímpicos de Londres, incluindo aqui uma importante entrevista com Carlos Arthur Nuzman, o presidente do Comitê Olímpico Brasileiro (COB) - relatar minhas inquietações e reflexões a respeito do contexto olímpico esportivo atual considerando a sólida e lamentável hierarquização institucional existente do Esporte sobre Escola, fato que parece comum no Brasil. Como Bracht (2007) argumentou sobre a lógica que define as ações no campo esportivo não sendo influenciadas pelos resultados educativos, destaco que os resultados esportivos geram influências bastante questionáveis no campo educacional. Meu argumento parte do entendimento essencial de que a Escola e a EF escolar devem proporcionar ao aluno uma formação crítica por meio do conhecimento e não formação de atletas por meio do esporte. 
Perpassa ainda, neste tex to, minha intenção em tornar o diálogo sobre megaeventos esportivos, o quanto possível, mais acessível aos diferentes grupos de leitores da Educação (Física), do Esporte, de outras áreas das Ciências Sociais e Humanas, ou ainda, aos leigos que se interessam pelo assunto. Para tal, e por se tratar ainda de uma publicação temática que envolve certa "polêmica", busquei neste trabalho um estilo de escrita "menos rígido" em alguns momentos, se comparados àqueles que costumamos observar em periódicos acadêmicos científicos.

\section{UMA BREVE CONTEXTUALIZAÇÃO HISTÓRICA DA EF E DA HEGEMONIA DOESPORTE}

Afirmou Michael Apple (2006, p. 35), destacado intelectual norte-americano, sobre a análise da hegemonia, que a abordagem mais proveitosa para se organizar o pensamento e a ação relativos à educação deve buscar

explicar os reflexos manifestos e latentes ou codificados dos modos de produção material, dos valores ideológicos, das relações de classe e das estruturas de poder social - racial, sexual e também político-econômico - sobre o nível de consciência das pessoas em uma determinada situação histórica ou socioeconômica.

Para além de sua complexidade, a ideia tem por essência refletir sobre o fato dos sistemas estruturais hegemônicos dominarem a vida cultural. Segundo o autor, "isso inclui práticas do cotidiano, como as escolas e o ensino e os currículos que adotam" (APPLE, 2006, p. 36). Dessa forma, torna-se compreensível que o esporte - assinalado aqui como um reflexo de estruturas mais amplas que compõem a sociedade moderna ou ainda, capitalista - e toda a influência gerada pela mídia a seu respeito, também se apresentam como parte integrante do processo de influência à vida cultural de uma sociedade, podendo contribuir para uma alienação generalizada. 
Não pretendo aqui, ignorar o caráter polissêmico do esporte, já tão afirmado na literatura (BRACHT, 2007). Portanto, ressalto ainda as concepções teóricas que o analisam como representação de uma cultura corporal, com significações divergentes. Assim como Bracht (2002, p. 193), julgo que as concepções destacadas, somam-se na composição de uma análise mais larga do fenômeno esportivo. Sustenta o autor ser "problemática a tendência de absolutizar uma das análises ou, então, permanecer na perspectiva da naturalização do esporte (o que tem um significado ideológico devastador)". Aceitar e incentivá-lo como algo universal significa eliminar seu aspecto histórico, obscurecendo a face socioeconômica (capitalista) e política, e que me parecem um tanto óbvias se buscarmos um olhar mais cauteloso. Tal eliminação me parece ser a mais apropriada na estratégia de sua legitimação (e manutenção) no interior da escola, e que é utilizada por grupos de indivíduos que detém o poder.

Mas se vamos falar em história, ao pensarmos o berço da EF na modernidade, logo lembraremos as intenções higienistas e militaristas que lhes perpassavam a essência dentro da escola. Bracht (1989, p. 14) destaca que "a Educação Física não desenvolveu a este tempo um corpo de conhecimentos que a diferenciasse fundamentalmente da instrução física militar". AEF escolar agregava esses valores. Do mesmo modo, o processo de esportivização ocorrido a partir da década de 1920 e que se intensificou no período pósguerra, incorporou ao campo novos códigos e funções. Estava a identidade da EF estabelecida com um meio-ambiente regido pelo cruzamento de três instituições: a Militar, a Esportiva e a Escolar. Parece-me lícito aceitar que existia uma clara hierarquia entre elas.

A partir da Revolução de 1964 e da tomada do poder pelos militares, a instituição escolar ganha mais visibilidade e é tida como um potente espaço de controle social e manutenção da ordem. Somado a este fato, está o apelo televisivo e jornalístico referente às questões do nacionalismo por meio da emulação esportiva. Com o cenário da Guerra Fria (Capitalismo X Socialismo), passa a ser fundamental para o Estado, ostentar uma sociedade forte, viril e pronta para a batalha. Assim, o esporte passa a ser a vitrine do 
momento, gerando como consequência básica uma EF escolar que absorve as características mais essenciais da competitividade.

Em meados dos anos de 1980, novas teorizações críticas são formuladas e o campo da EF passa a ser questionado sobre sua autonomia e sua conduta pedagógica (BRACHT, 1989; 2007). A situação de hegemonia do esporte como conteúdo essencial na EF escolar parece amenizar. Contudo, ainda não se observa uma superação do processo por parte dos profissionais da área. Ora, se a EF está inserida na instituição escolar, deveria então assumir seus códigos e funções. Parto do entendimento de que a função essencial da escola consiste em formar cidadãos críticos, aptos a pensar sobre si mesmos e sobre a sociedade na qual estão inseridos mediante, primordialmente, a aquisição de conhecimentos sistematizados e que são diferentes dos adquiridos no senso comum ou na esfera pessoal (YOUNG, 2011).

Assim posto, e como ferramenta essencial para tal intento, defendo a formação intelectual e multicultural dos professores de $\mathrm{EF}$, visando a capacidade de atenderem melhor tais necessidades educacionais. E ainda, que a EF seja uma das formas de se pensar o esporte como cultura - não só "corporal", pois o termo me parece sustentar a histórica dicotomia mente/corpo, a qual acredito ser a grande responsável pelo nascimento da crise na área - para além dos limites apenas reprodutores ainda vistos atualmente. Fato que não impede que ela possa continuar funcionando, de acordo com as características locais de um grupo, como um meio de aplicação técnica, teórica ou prática do conhecimento (VARGAS; MOREIRA, 2011). Sustento (e por que não?) que o professor de EF deva reconhecer e aceitar também o potencial técnico da área - o que não é "reducionista" - por sua grande facilidade em dialogar com diferentes teorias existentes nos múltiplos campos do saber. Julgo tal diálogo, naturalmente, enriquecedor em todos os sentidos. 


\section{Os Jogos OLíMPICOS DE LONDRES: REFLEXÕES SOBRE O ESPORTE E A EDUCAÇÃO}

Inicialmente, observemos apenas os 08 países melhores classificados como potências olímpicas em Londres: EUA, China, Grã-Bretanha, Rússia, Coréia do Sul, Alemanha, França e Itália. Será demasiado argumentar sobre o patamar educacional no qual estão a maioria destes países? Será um exagero compreendermos que as escolas e as universidades destas nações estão entre as melhores do mundo? Que os índices de analfabetismo, fome e mortalidade são baixíssimos? A despeito de nutrir um posicionamento mais crítico quanto à necessidade extrema de "classificações", no ranking de universidades ${ }^{1}$, por exemplo (e que deveria, em meu entendimento, ser muito mais valorizado do que o de medalhas), das nações citadas, somente a Itália e a Rússia não possuem instituições entre as 100 melhores existentes. Elementar ainda: EUA, GrãBretanha e Alemanha se destacam com suas inúmeras instituições superiores com alto índice avaliativo. Comparando com o Brasil, por exemplo, a USP - nossa melhor universidade - apareceu pela primeira vez entre as duzentas $\left(178^{\circ}\right.$ lugar). Agregue-se o fato de que a Unicamp, outro centro de referência de pesquisas no país, perdeu quase 40 posições ( $286^{\circ}$ lugar). Assim, parece-me clara a resposta para o que nos falta: vergonha política e crítica popular.

Contudo, gostaria de destacar que, ao longo das mais de duas semanas de competições olímpicas que aconteceram em Londres, fui agradavelmente surpreendido por algumas pessoas nas ruas, mercados, padarias, festas etc, os quais frequentei, posicionando-se criticamente em relação às questões levantadas anteriormente. Questionava-se, por exemplo, em um mercado de minha cidade, porque esses atletas deveriam estar lá em Londres, comendo e dormindo bem, enquanto as escolas públicas estão completamente abandonadas, enquanto as universidades passam por greves almejando melhores condições, enquanto tantas crianças estão

${ }^{1}$ http://www.usp.br/imprensa/wp-content/uploads/061020110002c12.jpg

Movimento, Porto Alegre, v. 18, n. 04, p. 309-325, out/dez de 2012. 
esquecidas nas ruas, enquanto se morre na porta dos hospitais. A título de exemplo, ouvi um senhor de "meia idade" dizer, após o segundo gol do México sobre o Brasil: "Isso mesmo, tem mais é que perder em tudo... porque na realidade a gente não tem é nada!". Fiquei escutando atento e resolvi dialogar... foi um momento ímpar perceber um cidadão do "país do futebol" realizar tal comentário.

Outros exemplos também podem ser aqui destacados, pois percebi a insatisfação de pequenos grupos também em outros ambientes. Me arrisco a dizer, que o fato da Rede Globo não transmitir os Jogos em canal aberto pode ter amenizado a alienação popular tão característica diante de megaeventos esportivos. $\mathrm{O}$ fato do desconhecimento de várias pessoas sobre o próprio acontecimento das Olimpíadas naquelas semanas já me parece um detalhe bastante significativo. A influência da mídia parece ter sido menos incisiva do que a realizada em momentos olímpicos anteriores. Observei, por exemplo, uma jovem comentar com colegas, em frente a uma banca de jornal, a respeito de sua própria surpresa ao ler a notícia da medalha de ouro conquistada pela ginástica brasileira já na segunda semana dos jogos (ela viu apenas a manchete no jornal da banca). Em suas palavras: "Gente, eu nem lembrava que estava tendo olimpíada".

Outro exemplo, incluindo jovens alunos, ocorreu numa escola que frequento. Nas aulas de EF, é comum os alunos acompanharem os destaques da NBA (o basquete norte americano) e comentarem nas aulas sobre os seus ídolos neste esporte: "Bryan, James, Wade, Howard, etc". Contudo, percebi que vários destes mesmos jovens não sabiam muitos detalhes sobre os jogos do Dream Team nas olimpíadas, muito menos sobre a boa participação técnica do basquete brasileiro após 16 anos fora das competições. Some-se a isso que, nas aulas de Judô, os discentes sequer sabiam os nomes dos atletas brasileiros medalhistas...

Destaco ainda mais um último ponto que me chamou a atenção: ao mesmo tempo em que os atletas brasileiros de voleibol (a geração de ouro), vencedores nos Jogos de Barcelona, desfilaram em carros abertos pelas ruas brasileiras em 1992 como heróis (de "quem"?), a 
derrota para a Rússia "de virada" na final olímpica, após dois sets técnica e taticamente excelentes do Brasil, parece ter sido muito pouco comentada, se comparada as finais anteriores nas quais a seleção participou. Isso tudo sem falar do pouco destaque dado a tão sonhada medalha de ouro no futebol, que mais uma vez não veio. Ironicamente, me arrisco a dizer que parece já estarmos "meio cansados" dessa espera. Contudo: "Essa ficou para o Rio! Nós vamos ganhar em casa!", disseram alguns jornalistas tentando disfarçar a própria insatisfação e manipular a opinião pública, quero dizer, incentivando a população a continuar acreditando que é possível (e assistindo a TV também, o que parece ser o mais fundamental). Eu gostaria mesmo de entender qual é diferença entre ganhar dentro ou fora do país, a despeito de pensar mesmo sobre a real necessidade ou importância do feito "ganhar uma medalha olímpica"?

Enfim, o que pretendo destacar é que, parte da população, mesmo que pequena, já parece perceber um pouco mais o quão "supérfluo" pode significar nos tornarmos uma potência esportiva como nossos governantes tanto insistem - em detrimento de outras condições mais essenciais. Ora, se o país tem tanto dinheiro para aplicar ao esporte, beneficiando uma clara minoria, porque não há para os outros campos, os quais são compostos pela esmagadora maioria?

\section{A entrevista de Nuzman...}

Cada macaco no seu galho.

(Ditado popular)

Em recente entrevista ${ }^{2}$, Carlos Arthur Nuzman, presidente do Comitê Olímpico Brasileiro (COB) e do Comitê Organizador Rio 2016, foi questionado sobre a relação da escola com o esporte na formação de atletas. Reconheço que isto é uma "velha" discussão... (mas que ainda não obteve "novas" respostas). Destacou-se no

\footnotetext{
${ }^{2}$ Entrevista exibida pelo Canal Sportv em 22/07/2012, coordenada pelo repórter Luiz Carlos Júnior.
} 
programa, o contexto norte americano de valorização do esporte escolar por meio de bolsas estudantis e sugeriu-se a possibilidade do Brasil adotar a mesma política. $\mathrm{O}$ entrevistador foi enfático em sua pergunta: "a escola passa pela formação de atletas?" Sem querer enfocar a má formulação da questão, que pareceu ocorrer mais pela circunstância "coloquial do bate-papo" televisivo (e considerando também que o jornalista em foco não é um profissional da área de Educação), sugiro apenas que a mesma poderia ter sido: "a formação de jovens atletas deve ser função da escola?", o que parece ter sido sua intenção de perguntar. Assim, destaco a longa, redundante e ambivalente resposta de Nuzman (que se aventurou a falar sobre Educação) e que merece reflexão e questionamento:

Eu fico muito à vontade para falar porque eu venho da escola. Eu não vim de clubes, eu fui para o clube depois. Eu acho que o caso dos EUA, da maneira como é ele, é o único do mundo. Mas a participação da escola eu defendo arduamente... no sistema desportivo - principalmente agora com as olimpíadas escolares que fazemos juntos - de que ela tem surgido e tem trazido inúmeros atletas para o esporte do Brasil de maneira geral. As escolas, historicamente, não tem instalações esportivas [...] e nem professores, mas eu vejo o caminho dessas olimpíadas escolares, que cada vez vai ser maior, cada vez mais intenso e cada vez mais importante na construção desse Brasil esportivo que nós precisamos: o Brasil esportivo que tem clubes, mas que tem que ter as escolas muito fortes e passar para o esporte universitário em muitas modalidades em que a idade permite que o atleta vá. (grifos meus)

Observe-se que Nuzman, inicialmente, se mostrou "à vontade", mas se esquivou de responder sobre a possibilidade de bolsas de estudo para alunos que realizam o esporte na escola. Se fosse realmente um interesse do Estado, preocupar-se com a real inserção social de um indivíduo por meio do esporte, julgo que a distribuição de bolsas escolares deveria ser, talvez, a primeira etapa. Assim, quando me deparo com a pobreza de uma argumentação no sentido 
descrito acima, pergunto se podemos mesmo acreditar que algum dia a Educação será prioridade no país. A despeito de reconhecer que Nuzman - um cidadão do esporte - não tem competência para abordar a questão escolar ou educacional, minha argumentação é legítima pelo fato dele - um homem público que ocupa um cargo de alto escalão do governo - apresentar claramente em sua fala a ideia de que escola deve participar do "sistema desportivo". Vou apresentar minha análise sobre a resposta do nosso presidente do COB em três etapas.

Em primeiro lugar, como destacado anteriormente (o mais elementar): será tarefa da escola dedicar parte do seu tempo com tais preocupações esportivas, se ela não cumpre o essencial, que consiste na formação do cidadão por meio do conhecimento? Qual será o futuro de uma sociedade que não prioriza a Educação e o conhecimento escolar ou mesmo as pesquisas em universidades? Michael Young (2011, p. 5), um dos mais importantes estudiosos da educação na Inglaterra, é enfático ao afirmar que "a finalidade mais fundamental da educação escolar [...] é levar os alunos para além de sua experiência por formas às quais eles dificilmente teriam acesso em casa". Assim, pergunto: os jovens já não possuem demasiado acesso ao conteúdo esportivo por meio da mídia, por exemplo? Leiase bem: Copa do Mundo, Olimpíadas, Campeonato Brasileiro de Futebol, Taça Libertadores da América, Novo Basquete Brasil (NBB), Basquete Norte Americano (NBA), Vôlei de Praia, eventos de Artes Marciais Mistas (MMA) etc, enfim, uma quantidade enorme de megaeventos esportivos está disponível aos jovens na TV (e na internet). Assim, questiono: deverá também, tal conteúdo, ser apenas "reproduzido" pela escola? Evidente que não.

Em segundo lugar: se as escolas não têm instalações e nem professores capacitados - como reconhece claramente o presidente do COB - será a organização de olimpíadas escolares o melhor caminho? Em minha avaliação, a resposta seria positiva unicamente para encontrarmos atletas mirins com características adequadas aos padrões modernos de esporte de rendimento, ou seja, um caminho que trará visibilidade e lucro para uma minoria pré-estabelecida (visto 
que na própria entrevista foi polemizada, pelos argutos jornalistas, a questão sobre as eleições para o cargo que Nuzman ocupa, quero dizer, foi questionada sua legitimidade democrática), mas que ao final, continuará fomentando a segregação de crianças em idade escolar. Os que não têm "perfil" atlético, não servem para tais ideais - o que não seria um problema se estes mesmos jovens não ficassem sem as mesmas boas condições que os novos atletas mirins passariam a ter simplesmente por já serem dotados de "boas capacidades biológicas", já que estes poucos jovens passariam a ter melhores condições básicas de vida fomentadas pelo governo e pela iniciativa privada.

Portanto, pergunto, no que tange a esfera pública: quem decide esta aplicação de verba ou de investimentos, por exemplo, em Olimpíadas Escolares? Por quais razões o Estado investiria mais em crianças habilidosas do ponto vista físico e motor, levando-as ao esporte de rendimento, em detrimento de crianças menos favorecidas geneticamente? A resposta me parece tão óbvia quanto à tentativa de Nuzman em obscurecer os fatos. Eis aqui um dos grandes problemas do país: a opressão me parece diretamente (e cada vez mais) proporcional à desigualdade, seja no campo que for. Quanto maiores as diferenças entre indivíduos, que no caso da Educação Física e do esporte, são biológicas, ainda mais excluídos e esquecidos ficam os desfavorecidos. Ironicamente, lembro-me da sociedade espartana, que assassinava crianças que não serviam para a guerra.

Em terceiro lugar, e retomemos a fala de Arthur Nuzman: que pensar sobre a intenção da "construção desse Brasil esportivo que nós precisamos: o Brasil esportivo que tem clubes, mas que tem que ter as escolas muito fortes"? Quem precisa, Sr. Carlos Nuzman, desse Brasil esportivo? Que "nós" é esse? Faltou essa explicação para o público. Um Brasil com escolas muito fortes? Como assim? Escola forte é a que produz atletas? No contexto já caótico da escola brasileira, de falta de comprometimento com o que deve ser ensinado para um aluno, de professores mal preparados e mal remunerados, que podemos concluir? Respondo: manutenção do caos e a 
permanência de grupos estabelecidos no poder político e econômico. Quem já está inserido, quem já está acima, no domínio... enfim, estes não abrem mão do poder. Permita-me o leitor dizer num jargão mais popular: "o cachorro que não quer largar o osso".

Considerando ainda o contexto atual de debate acadêmico educacional, pergunto ao Sr. Nuzman: que identidades serão construídas dentro das escolas nessa perspectiva político-ideológica? Serão as almejadas pelo projeto moderno? O atleta forte, centrado na racionalidade, disciplinado, controlado e/ou forjado pelos (caríssimos) métodos avançados de treinamento esportivo? Por que não o incentivo a construção de uma identidade mais "pós-moderna" de aluno? Quero dizer, a de um sujeito mais flexível e que se posicione para além da concepção centrada unicamente na razão e no condicionamento físico? Um aluno que se reconheça um indivíduo também "subjetivo" e que possa ser crítico diante do mundo e de sua posição nesse mundo. Que identifica seus desejos, suas vontades, mesmo que sejam estas o devir atleta. Contudo e para tal, me parece fundamental oferecer-lhe, acima de tudo, acesso ao conhecimento, e ainda, instigar-lhe uma compreensão sobre a luta existente entre nossas subjetividades, e destas contra a insistente objetividade do "lugar que devemos ocupar" em um cenário ainda moderno, porém mais reflexivo, ou seja, que já é de transformações (VARGAS, MOREIRA, 2011).

Em síntese, abordo aqui uma potencialização, o quanto possível mais responsável, do livre arbítrio e de um entendimento de que estamos inseridos em um sistema monocultural construído política e economicamente por minorias, sendo o Esporte um dos "pilares notáveis" dessa estrutura. Julgo assim, que a escola e a universidade devam ser ambientes onde se favoreçam novas formas de pensar o mundo em seus múltiplos campos, com acesso ao conhecimento sistematizado e oferecendo sempre novos caminhos que objetivem possíveis transposições paradigmáticas que possam abalar as colunas deste sistema estrutural exageradamente rígido. 


\section{Considerações FinaIS}

Quero destacar que não tenho, sob nenhuma hipótese, a intenção de utilizar minha argumentação para desqualificar o esporte. Não se trata disso, mas sim analisar e questionar as relações hierárquicas do Esporte sobre a Escola, que são instituições independentes (ou pelo menos deveriam ser). Entendo e sustento que Esporte é uma coisa e Educação é outra. Não será demais aceitarmos passivamente essa imposição acrítica de valores e condutas referentes à rivalidade, competição a todo tempo, culto excessivo ao corpo etc., no interior escolar? Deverá a escola formar atletas ou fomentar acesso ao conhecimento (MOREIRA, 2007; YOUNG, 2011), tornando o aluno mais crítico e emancipado? Não deveriam os nossos jovens em idade escolar, entender também as relações, por vezes sibilinas, que ocorrem por debaixo do "véu festivo" de intenções empresariais e mercadológicas em um cenário neoliberal?

Alerto também o leitor contra o (pseudo) argumento (mesmo que pouco, mas ainda utilizado em ambientes mais leigos ou mesmo na própria escola) de que o Esporte educa e é bom para saúde. Ressaltou Bracht (2002, p. 195), que "toda instituição social precisa, para perdurar no tempo, convencer 'a sociedade' da importância da sua função. Para isso o esporte fez seu discurso médico e pedagógico [...]". Ora, o esporte não é uma entidade mágica com poderes educacionais, mas antes os professores escolares que poderão concretamente utilizá-lo para algum fim específico (reconheço que atrelado às suas subjetividades), e que sustento aqui em nossa pauta educativa, deva ser o da formação crítica, do fomento à autonomia de um jovem em idade escolar. Por isso o investimento deve ser no professor.

Quanto à saúde, defendo a prática moderada e regular do exercício, mas questiono também: será demais lembrarmos os inúmeros problemas que o esporte de alto rendimento pode causar? Dores, insônia, ansiedade, fadiga excessiva, problemas articulares irreversíveis, distenções musculares, uso de drogas etc. Inúmeros trabalhos já alertaram sobre os perigos oriundos dos excessos 
esportivos (WEINBERG; GOULD, 2001). O leitor terá a real noção a quais procedimentos e rotinas um atleta de rendimento olímpico se submete?

Outros exemplos de consequências negativas do mau uso do esporte na escola podem ser aqui relatados. Já presenciei, por exemplo, em minha trajetória profissional, alunos que "matavam aulas" para participar de eventos esportivos escolares. Isso sem mencionar os professores de EF que, afoitos por resultados esportivos, por vezes, aceitam, incentivam e acobertam tais atitudes dos discentes. Não deveria a escola proporcionar a participação do estudante em seus eventos, sem o prejuízo da perda de aulas? Que educação é esta que o esporte favorece? Ou será apenas a própria decisão do aluno e/ou do professor? O esporte pode ser responsabilizado pelas decisões dos indivíduos? Em que medida as ambivalências dos educadores físicos causadas pela crise de identidade epistemológica da profissão (VARGAS; MOREIRA, 2011) prejudicam as crianças submetidas às suas responsabilidades?

O que quero destacar é que, para além do livre arbítrio de cada indivíduo escolher seu caminho, julgo fundamental apresentar os múltiplos possíveis caminhos, principalmente dentro da escola, para as crianças que ainda são desprovidas de um senso crítico aprimorado. Cabe a Educação investir no potencial de escolha dos alunos. Contudo (e trivial), isso não parece ser um interesse do Estado ou da iniciativa privada que lucra com o Esporte.

Uma última questão, para o caso da argumentação conservadora daqueles que se apropriam do discurso de que o esporte serve como veículo de inserção social. A despeito de concordar, defendo ainda com mais ênfase que a maior inserção ocorrerá pelo conhecimento escolar adquirido. Pergunte-se o leitor: quantos indivíduos no país se destacam profissionalmente por terem passado por uma boa educação e quantos "vingam" como atletas realizados profissionalmente? Será comum observarmos atletas ainda jovens sem patrocínio e sem boas condições para trabalhar em outras áreas porque trocaram seus estudos por treinamento físico-esportivo? Parecem-me claras as respostas. Tão claras quanto os "reais" 
motivos de todo o dinheiro investido no esporte em detrimento das escolas e universidades. Se pensarmos novamente nas nações que disputam medalhas e que encabeçam o quadro olímpico hoje, verificaremos que já são potências na área educacional (e de pesquisas) há muito tempo.

A título de encerramento deste ensaio, e completando todos os meus argumentos, destaco o excelente texto de Arlei Damo (2012), publicado recentemente nesta revista, denunciando com profunda propriedade a face obscura dos megaeventos esportivos que ocorrerão no país no próximo ciclo olímpico. Ressalto, mesmo que num trecho mais longo, suas próprias (e pertinentes) palavras:

Para um país como o Brasil, sediar a Copa e as Olimpíadas em tão curto espaço de tempo soa um tanto extravagante. Parece irracional que uma nação com sérios entraves nas áreas da saúde, moradia, educação, segurança e tantas outras, subtraia delas um centavo que seja para empenhá-lo na preparação de um megaevento esportivo, quanto mais em dois. (...) são tão poucas as vozes que manifestam contrariedade que seria o caso de nos perguntarmos se não estamos todos mistificados pela mídia, pelo marketing esportivo, pela propaganda dos governos e, sabe-se lá, por quais outras forças misteriosas [...] os chefes estão dispondo da riqueza de seu povo para bancar de um ritual extravagante, que veicula sentimentos de orgulho e poder, um espetáculo de pura exuberância e luxúria, e talvez por isso tolerado e mesmo incentivado. (DAMO, 2012, p. 77-78).

Finalizo afirmando que eu prefiro nosso país na condição de "verdadeiras" potências como Áustria, Canadá, Suécia, Bélgica, Finlândia, Dinamarca, Suíça, Noruega, entre outros... nações quase ou sem medalhas olímpicas, mas com qualidade de vida, Saúde e Educação. Assim, caros leitores, após toda a comemoração dos ouros olímpicos, após toda nossa atenta e intensa torcida diante da TV - e, principalmente, após assistirmos alheados os milhões de reais que saíram do nosso país - curtam a verdade: a nossa vida continua... na mesma! 
Gold sport and "old iron" education: our life continues... in the same!

Abstract: This paper aims to reflect on Olympic sports context, considering the hierarchy of the institutional between sports over school, a common fact in Brazil. The article draws on recent works of renowned intellectuals, as well as close observation of television coverage of the London Olympics, including an interview with Carlos Nuzman, President of the Brazilian Olympic Committee (COB). Bracht argued that the logic that defines the action on the sports field is not influenced by educational attainment. Taking this argument into account, it is suggested that the results demonstrate that sports generate enough questionable influences on the educational field.

Keywords: Sports. Education. Knowledge. Olympic Games.

Deporte de oro y educación "de hierro viejo": nuestra vida continúa... en la misma!

Resumen: Este trabajo tiene como objetivo reflexionar sobre el Olympic contexto deportivo actual teniendo en cuenta la jerarquía deportiva institucional en relación al pensamiento de las escuelas. Para eso, se sostiene en el trabajo reciente de intelectuales de renombre, así como una observación de la cobertura televisiva de los Juegos Olímpicos de Londres, incluyendo aquí una entrevista con Carlos Arthur Nuzman, presidente del Comité Olímpico Brasileño. Bracht argumenta que las acciones en el campo deportivo no están influenciadas por el nivel de instrucción, los resultados ponen de manifiesto que el deporte genera influencias cuestionables en el campo educativo.

Palabras-clave: Deportes. Educación. Conocimiento. Juegos Olímpicos 


\section{REFERÊNCIAS}

APPLE, Michael. Ideologia e currículo. 3. ed. Porto Alegre: Artmed, 2006.

BRACHT, Valter. Educação física e ciência: cenas de um casamento (in)feliz. 3. ed. ljuí, RS: Ed. Unijuí, 2007.

BRACHT, V. Esporte, história e cultura. In: PRONI, M., LUCENA, R. (Org.). Esporte: história e sociedade. Campinas, SP: Autores Associados, 2002.

Educação Física: a busca da autonomia pedagógica. Revista da Fundação de Esporte e Turismo, v. 1, n. 2, p. 12-19, 1989.

DAMO, Arlei. O desejo, o direito e o dever: a trama que trouxe a Copa ao Brasil. Revista Movimento, Porto Alegre, v. 18, n. 2, p. 41-81, abr./jun. 2012.

FOUCAULT, Michael. A ordem do discurso: aula inaugural no Collège de France, pronunciada em 2 de dezembro de 1970. 17. ed. São Paulo: Loyola, 2008.

MOREIRA, A. F. B. A importância do conhecimento escolar em propostas curriculares alternativas. Educação em Revista, Belo Horizonte, v. 45, p. 265-290, jun. 2007.

VARGAS, C. P.; MOREIRA, A. F. B. Identidades em desalinho: um estudo de campo na formação em Educação Física. Educação Unisinos, São Leopoldo, v. 15, n. 3, p. 215-224, set/dez, 2011.

WEINBERG, R., GOULD, D. Fundamentos da psicologia do esporte e do exercício. 2. ed. Porto Alegre: Artmed, 2001.

YOUNG, M. F. D. O futuro da educação em uma sociedade do conhecimento: o argumento radical em defesa de um currículo centrado em disciplinas. Revista Brasileira de Educação, Rio de Janeiro, v. 16, n. 48, dez. 2011.

Endereço para correspondência:

Avenida Presidente Itamar Franco, n. 285 / apto 101

Centro - Juiz de Fora, MG.

CEP: $3610-020$

Recebido em: 04.09.2012

Aprovado em: 20.10.2012

ovimento, Porto Alegre, v. 18, n. 04, p. 309-325, out/dez de 2012. 
